\title{
Extreme Programming Dalam Perancangan Sistem Informasi Jasa Fotografi
}

\author{
Doni Andriansyah*1, Lukman Nulhakim ${ }^{2}$ \\ ${ }^{1}$ Program Studi Teknik Informatika STMIK Nusa Mandiri \\ ${ }^{2}$ Program Studi Sistem Informasi STMIK Antar Bangsa

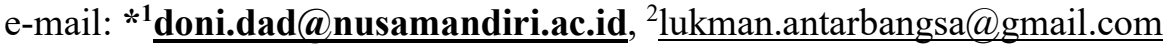

\begin{abstract}
Abstrak
Jasa termasuk kedalam sektor perdagangan yang cukup banyak pelaku usahanya. Tak jarang banyak pelaku usaha yang saling adu strategi untuk memenangkan persaingan bisnis. Salah satunya adalah dengan memanfaatkan teknologi informasi. Website merupakan media yang paling banyak mereka gunakan dalam mempromosikan jasa yang mereka tawarkan. Hal ini tentu saja untuk menjawab permasalahan klasik yang timbul, yaitu pelanggan diharuskan datang langsung ke workshop untuk melakukan pemesanan jasa. Pencatatan transaksi masih dilakukan secara manual sehingga sangat rentan rusak, tercecer, atau bahkan hilang. Tujuan penelitian ini adalah untuk membangun sebuah website yang mampu melayani pemesanan jasa oleh pelanggan dan melakukan pencatatan secara otomatis. Metode yang digunakan dalam pengembangan sistem adalah Extreme Programming yang terdiri dari tahapan perencanaan, perancangan, pengkodean, dan pengujian.
\end{abstract}

Kata Kunci- extreme programming, jasa, sistem informasi, fotografi

\begin{abstract}
Services included in the trade sector are quite a lot of business people. Not infrequently many business actors compete with each other on strategies to win business competition. One of them is by utilizing information technology. Website is the most used media in promoting the services they offer. This is of course to answer the classic problems that arise, namely customers are required to come directly to the workshop to order services. Transaction recording is still done manually, so it is vulnerable to damage, scatter, or even loss. The purpose of this research is to build a website that is capable of serving customer orders and records automatically. The method used in system development is Extreme Programming which consists of planning, designing, coding, and testing stages.
\end{abstract}

Keywords - extreme programming, services, information systems, photography

\section{PENDAHULUAN}

Teknologi dan sistem informasi saat ini tidak dapat dipisahkan dan telah menjadi kebutuhan yang utama dalam menjalankan proses bisnis. Penyelesaian sebuah permasalahan [1] kini beralih dari cara-cara konvensional menjadi cara-cara modern dengan memanfaatkan teknologi informasi. Maka tak jarang banyak perusahaan berlomba-lomba merekrut para lulusan IT untuk mengembangkan perangkat lunaknya sendiri guna memenuhi kebutuhan sistem informasi [2].

Tolak ukur keberhasilan perusahaan jasa dalam menghadapi persaingan adalah ketika dapat memberikan pelayanan terbaik [3] sehingga dapat memberikan nilai lebih bagi perusahaan. Salah satu jenis usaha kecil menengah yang menawarkan pelayanan jasa adalah penyedia layanan fotografi. Seiring dengan perkembangan zaman, jasa fotografi tidak hanya sebatas pada hasil foto formalitas seperti foto untuk prasyarat pengurusan dokumen, namun 
lebih kepada kebutuhan dokumentasi pelanggan saat ini seperti foto pre-wedding, foto wedding, dan lain sebagainya.

Jika sebelumnya pelanggan diharuskan datang langsung ke workshop fotografi untuk dapat memesan jasa tersebut, dengan diterapkannya sistem informasi proses pemesanan dapat dilakukan dengan efektif dan efisien, setiap orang dapat dengan mudah memperoleh informasi layanan yang up-to-date dengan cepat [4], bahkan hanya dengan berada dirumah saja. Disamping itu, proses pencatatan pembayaran masih dilakukan secara manual, selain rentan hilang, rusak, atau tercecer, proses pencatatan manual dikhawatirkan mengalami kekeliruan didalam pencatatannya.

Website merupakan salah satu inovasi yang tepat sebagai media penunjang [5] dalam memasarkan layanan jasa, jangkauan yang luas, dapat diakses kapanpun dan dimanapun menjadikan website pilihan tepat dalam menjalankan proses bisnis, khususnya bidang pelayanan jasa.

Tujuan dari penelitian ini adalah membangun sebuah website yang dapat memasarkan jasa fotografi menggunakan metode Extreme Programming (XP) sehingga dapat memberi kemudahan baik kepada pelanggan dalam melakukan pemesanan layanan maupun bagi pelaku industri dalam mengelola bisnisnya.

\section{METODE PENELITIAN}

Extreme Programming (XP) merupakan sebuah pendekatan dalam pengembangan perangkat lunak yang mencoba menyederhanakan berbagai tahapan dalam proses pengembangan tersebut sehingga menjadi lebih adaptif dan fleksibel. Metode ini mengedepankan proses pengembangan yang lebih responsif terhadap kebutuhan konsumen dibandingkan dengan metode-metode tradisional lainnya Wells dalam [4].

XP cenderung menggunakan pendekatan berorientasi objek, metode ini mengharuskan adanya tim baik dalam skala kecil hingga medium. Pendekatan XP sangat cocok jika tim dihadapkan pada requirement yang tidak jelas ataupun jika terjadi perubahan-perubahan requirement yang sangat cepat Prabowo et al. dalam [6].

Extreme Programming memiliki tahapan-tahapan sebagai berikut Schach dalam [7]:

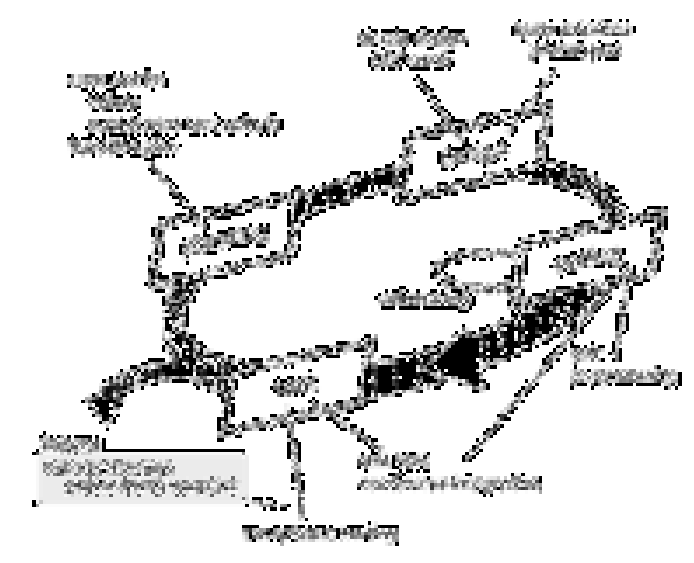

Gambar 1. Metode Extreme Programming.

a. Perencanaan (Planning)

Tahapan ini memiliki beberapa kegiatan perencanaan diantaranya mengidentifikasi permasalahan, menganalisa kebutuhan pengguna dan kebutuhan sistem, sampai dengan ditetapkannya jadwal pelaksanaan pengembangan sistem.

b. Perancangan (Design) 
Tahapan ini merupakan bagian dari perancangan sistem dimana dilakukan pemodelan sistem dan pemodelan arsitektur sistem menggunakan diagram Unified Modelling Language (UML), serta pemodelan basis data menggunakan Entity Relationship Diagram (ERD) dan Logical Record Structure (LRS).

c. Pengkodean (Coding)

Tahapan ini merupakan implementasi dari perancangan sistem yang telah dibuat kedalam bentuk user interface menggunakan bahasa pemrograman. Dalam penelitian ini bahasa program yang digunakan adalah PHP dengan metode Object Oriented Programming (OOP) dan basis data MySQL.

d. Pengujian (Testing)

Tahapan pengujian merupakan tahapan untuk menguji fungsionalitas sistem untuk mengetahui apakah sistem sudah sesuai dengan yang diharapkan oleh pengguna, dan untuk mengetahui apakah ada kesalahan lain yang timbul pada sistem ketika dijalankan. Metode pengujian yang digunakan adalah metode black box testing. Setelah melewati serangkaian pengujian dan hasilnya dapat diterima oleh pengguna, maka sistem siap untuk di release.

\section{HASIL DAN PEMBAHASAN}

Metode Extreme Programming yang digunakan memiliki empat tahapan dimulai dari tahapan perencanaan (planning), perancangan (design), pengkodean (coding), dan pengujian (testing). Tahapan tersebut dapat dilihat pada skema dibawah ini:

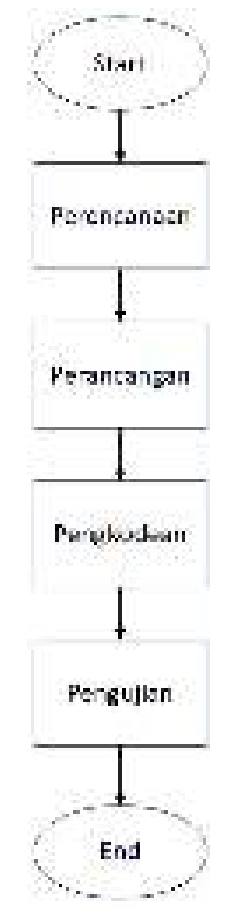

Gambar 2. Skema Tahapan Extreme Programming.

a. Perencanaan (Planning)

1) Identifikasi Masalah

Berdasarkan hasil observasi dan wawancara yang dilakukan dengan pemilik, maka dapat diidentifikasikan permasalahan saat ini sebagai berikut:

a) Proses pencatatan transaksi pemesanan dilakukan dengan mengisi form order manual. 
b) Proses pembuatan laporan pemesanan masih dilakukan secara manual menggunakan form rekap order.

c) Pembuatan bukti bayar / invoice untuk pelanggan masih manual.

2) Analisa Kebutuhan

Ditinjau dari permasalahan yang ada saat ini, maka dapat didefinisikan analisa kebutuhan masalah, yaitu analisa kebutuhan fungsional dan analisa kebutuhan nonfungsional.

Analisa Kebutuhan Fungsional

a) Sistem menyediakan form order sesuai dengan format manual yang diberikan agar pelanggan dapat melakukan pemesanan secara online.

b) Sistem mampu menyajikan laporan pemesanan secara otomatis dalam format Excel.

c) Sistem mampu menampilkan dan menyediakan bukti bayar / invoice versi cetak dalam format PDF.

Analisa Kebutuhan Non-Fungsional

a) Tipe pengguna terbagi kedalam dua level, yaitu level admin dan level user sebagai pengguna biasa. Seluruh pengguna diharuskan login terlebih dahulu sebelum dapat menggunakan sistem.

b) Pelanggan yang sudah melakukan pemesanan secara otomatis memiliki akses ke halaman pelanggan untuk mengetahui status order dan pembayaran, serta akses untuk dapat mencetak bukti bayar / invoice.

b. Perancangan (Design)

Pemodelan Sistem

1) Use Case Diagram

Interaksi yang terjadi antara aktor dengan sistem dapat dilihat melalui Use Case Diagram dibawah ini.

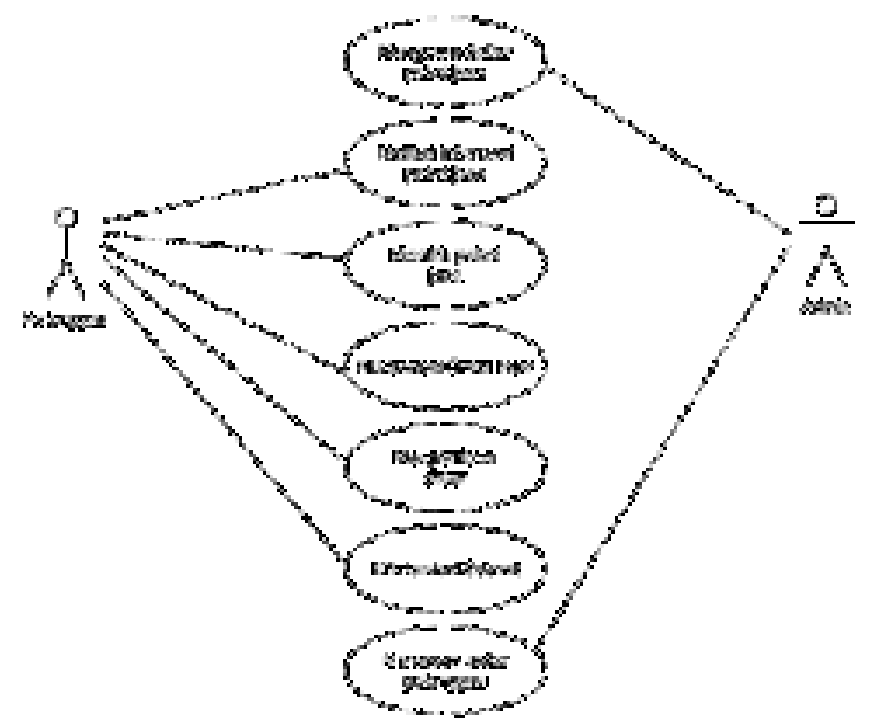

Gambar 3. Use Case Diagram Pemesanan Paket Jasa.

Tabel 1. Skenario Use Case Diagram Pemesanan Paket Jasa.

\begin{tabular}{|c|c|c|c|}
\hline No. & Use Case & Aktor & Skenario \\
\hline 1 & Mengelola daftar & Admin & Mengelola daftar paket jasa, termasuk \\
\hline
\end{tabular}




\begin{tabular}{|c|l|l|l|}
\hline & paket jasa & $\begin{array}{l}\text { didalamnya menambah, mengubah/update, } \\
\text { dan menghapus paket jasa. }\end{array}$ \\
\hline 2 & $\begin{array}{l}\text { Melihat informasi } \\
\text { paket jasa }\end{array}$ & Pelanggan & $\begin{array}{l}\text { Melihat informasi paket jasa melalui } \\
\text { halaman website dengan meng-klik tombol } \\
\text { More pada menu Packages. }\end{array}$ \\
\hline 3 & Memilih paket jasa & Pelanggan & $\begin{array}{l}\text { Memilih paket jasa yang ingin dipesan oleh } \\
\text { pelanggan melalui halaman website. }\end{array}$ \\
\hline 4 & $\begin{array}{l}\text { Klik tombol Order } \\
\text { Now }\end{array}$ & Pelanggan & $\begin{array}{l}\text { Mengklik tombol Order Now untuk } \\
\text { melakukan pemesanan paket jasa secara } \\
\text { online. }\end{array}$ \\
\hline 5 & Mengisi form order & Pelanggan & $\begin{array}{l}\text { Mengisi data diri pelanggan melalui form } \\
\text { order yang disediakan. }\end{array}$ \\
\hline 6 & Klik tombol Submit & Pelanggan & $\begin{array}{l}\text { Mengklik tombol Submit setelah selesai } \\
\text { mengisi form order. }\end{array}$ \\
\hline 7 & $\begin{array}{l}\text { Merespon order } \\
\text { pelanggan }\end{array}$ & Admin & $\begin{array}{l}\text { Merespon order yang dilakukan pelanggan } \\
\text { dengan merubah status order pelanggan } \\
\text { melalui halaman administrator. }\end{array}$ \\
\hline
\end{tabular}

2) Activity Diagram

Untuk mengetahui alur proses pemesanan paket jasa yang dilakukan oleh pelanggan, dapat dilihat pada activity diagram dibawah ini.

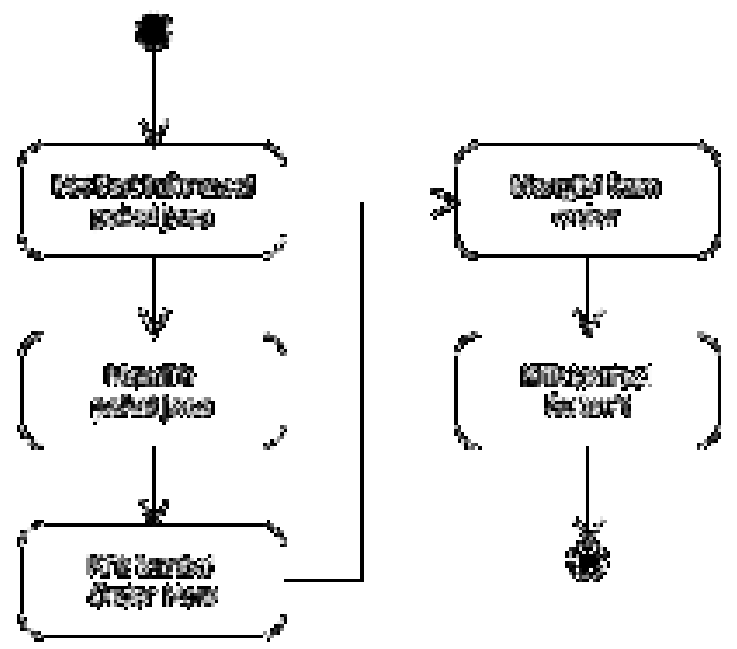

Gambar 4. Activity Diagram Pemesanan Paket Jasa.

Pemodelan Arsitektur Sistem

1) Deployment Diagram

Hubungan antara perangkat lunak (software) dengan perangkat keras (hardware) yang diimplementasikan dalam Sistem Informasi Jasa Fotografi dapat di visualisasikan melalui Deployment Diagram dibawah ini. 


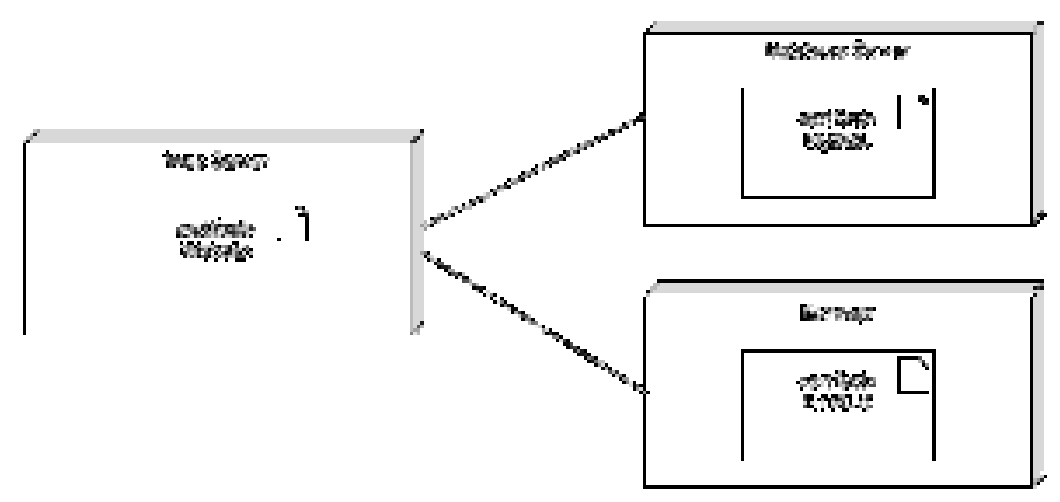

Gambar 5. Deployment Diagram Sistem Informasi Jasa Fotografi.

\section{Pemodelan Basis Data}

1) Entity Relationship Diagram (ERD)

Pemodelan Entity Relationship Diagram (ERD) digunakan untuk mengetahui hubungan yang terjadi antar suatu tabel didalam basis data. Berikut hubungan antar tabel yang terjadi didalam Sistem Informasi Jasa Fotografi.

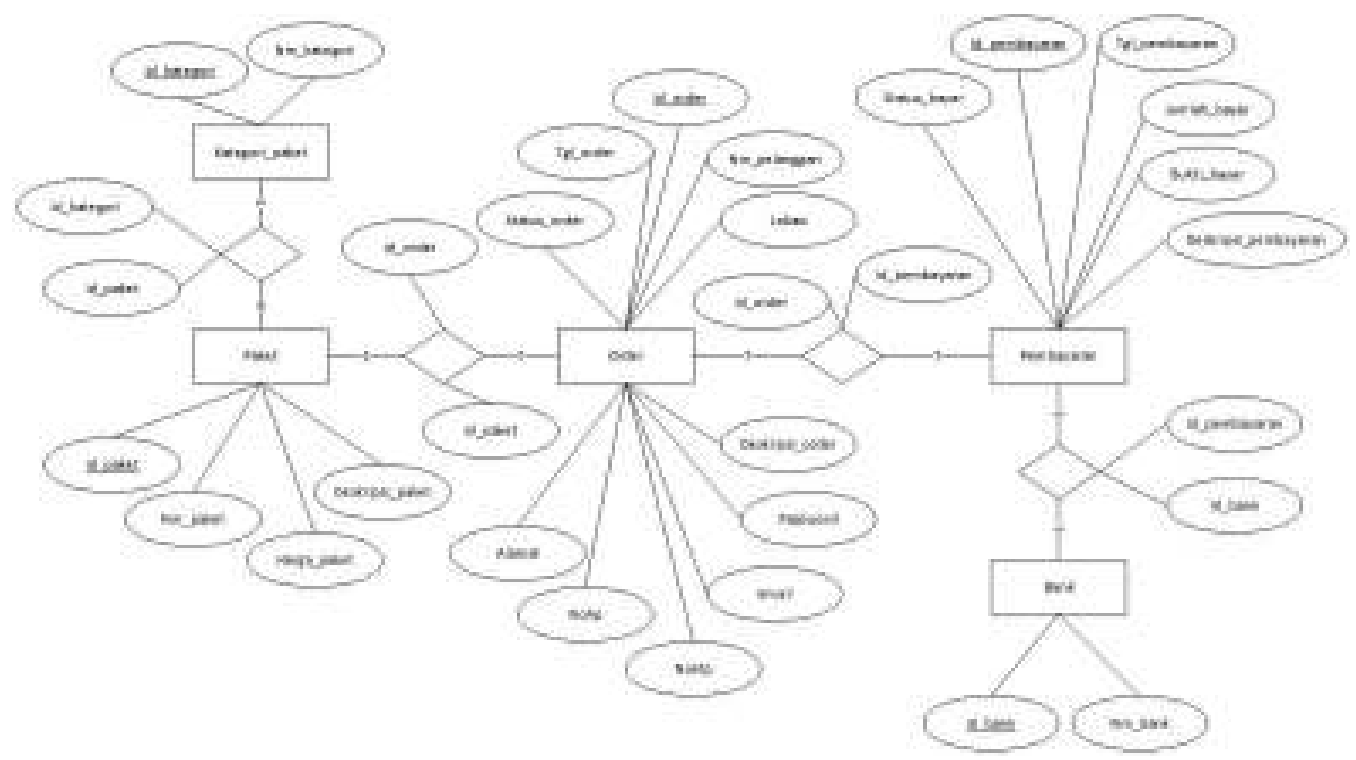

Gambar 6. ERD Sistem Informasi Jasa Fotografi.

\section{2) Logical Record Structure (LRS)}

Pemodelan Logical Record Structure (LRS) merupakan representasi dari struktur record pada tabel-tabel yang terbentuk dari hasil antar himpunan entitas, dapat dikatakan representasi dari hasil ERD. Berikut model LRS untuk Sistem Informasi Jasa Fotografi. 


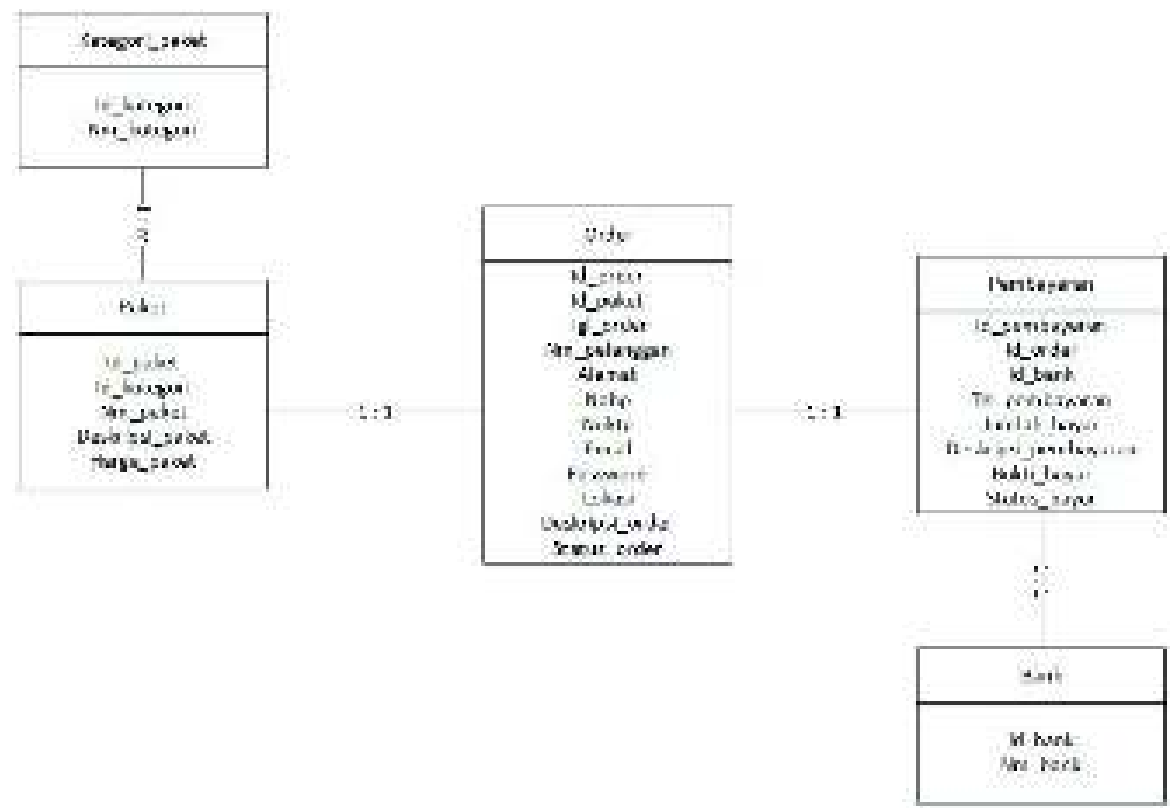

Gambar 7. LRS Sistem Informasi Jasa Fotografi.

c. Implementasi sistem berbasis website menggunakan bahasa pemrograman PHP dan MySQL dengan pendekatan berbasis objek (OOP).

1) Menu Paket Jasa

Pada halaman paket menampilkan daftar paket dengan informasi nama paket, kategori paket, dan harga paket. Terdapat tombol More untuk mengetahui informasi lebih lanjut dan tombol Order Now untuk melakukan pemesanan
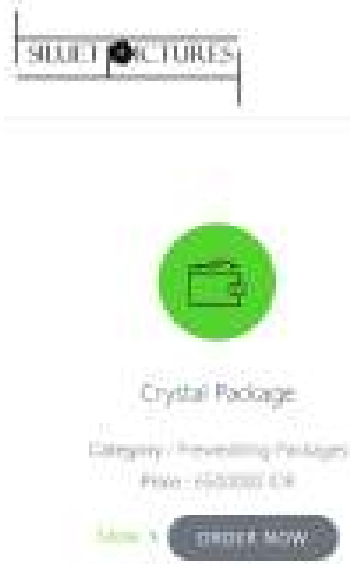

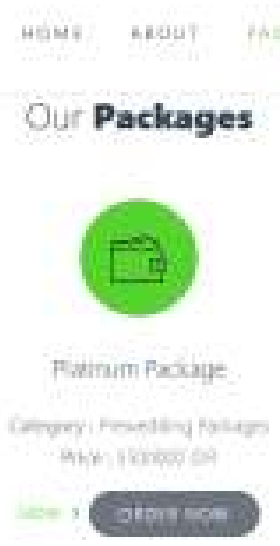

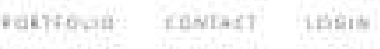

Gambar 8. Halaman Paket Jasa.

2) Deskripsi Paket

Halaman dibawah ini memperlihatkan deksripsi secara lengkap mengenai informasi paket yang dapat dilihat oleh pengunjung website engan cara mengklik tombol More.

Gambar di bawah ini menampilkan halaman form pemesanan yang disediakan untuk pelanggan, pengisian melalui form ini akan ditindak lanjuti oleh admin dengan menghubungi pihak pemesan melalui nomor HP yang diberikan. 


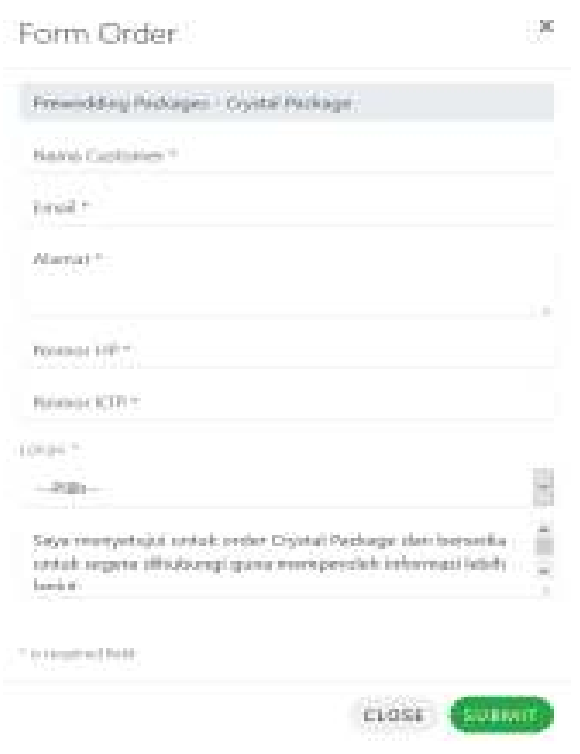

Gambar 10. Halaman Form Order.

3) Bukti Bayar / Invoice Pelanggan

Pelanggan dapat melihat dan mencetak bukti bayar / invoice atas pembayaran yang telah dilakukan dengan terlebih dahulu melakukan login ke halaman khusus pelanggan. Bukti bayar tersedia dalam format PDF.

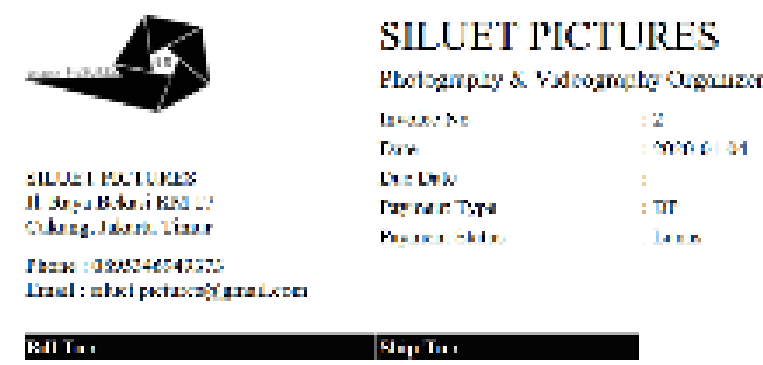

aneatian

masav

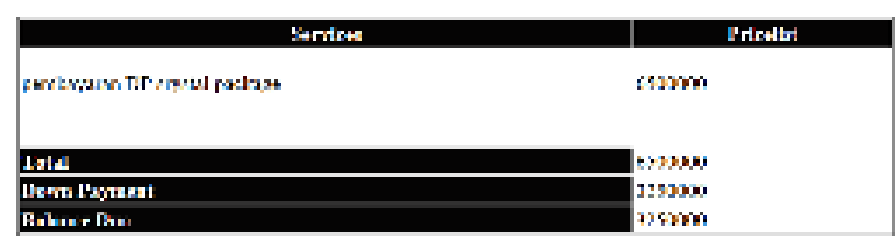

$$
\begin{aligned}
& \text { Towere Shass: } \\
& \text { ivis } \\
& \text { Nólini }
\end{aligned}
$$

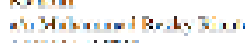

$$
\begin{aligned}
& 2 \text { ror } \\
& \text { sh Howerustertstion } \\
& \text { ss : } 2111 \text { sil }
\end{aligned}
$$

Thanks For Reservation

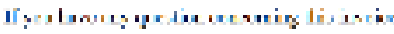
Ciscestez

Gambar 11. Bukti Bayar Pelanggan. 
4) Laporan Pemesanan

Admin dapat melihat dan mencetak laporan pemesanan ketika dibutuhkan. Laporan pemesanan versi cetak tersedia dalam format Excel.

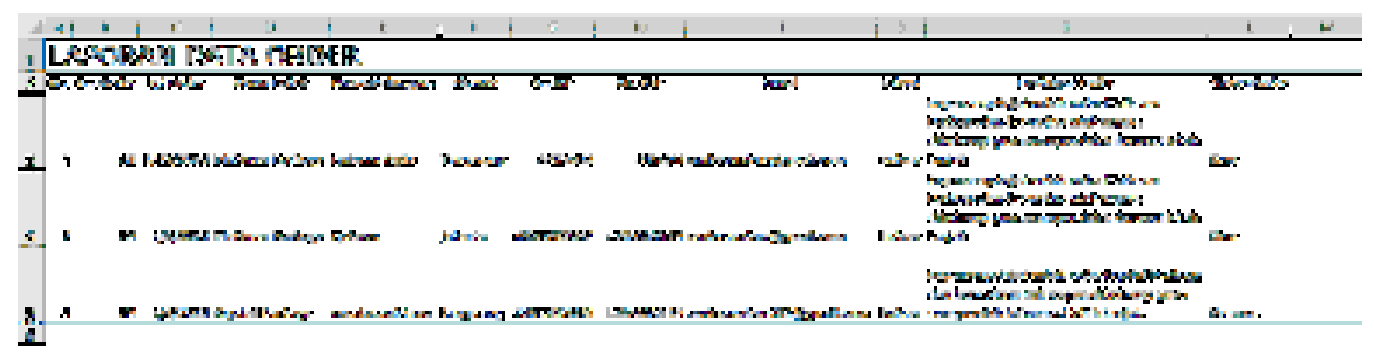

Gambar 12. Laporan Pemesanan.

d. Pengujian (Testing)

Pengujian dilakukan menggunakan pendekatan black box testing untuk menguji apakah fungsionalitas sistem sesuai dengan yang diharapkan. Halaman yang diujikan adalah halaman Form Order.

Tabel 2. Tabel Hasil Pengujian Black Box

\begin{tabular}{|l|c|c|c|}
\hline \multicolumn{1}{|c|}{ Test Case } & $\begin{array}{c}\text { Expected } \\
\text { Result }\end{array}$ & Result & Conclusion \\
\hline $\begin{array}{l}\text { Nama customer tidak boleh } \\
\text { kosong }\end{array}$ & $\mathrm{T}$ & $\mathrm{T}$ & $\mathrm{Ok}$ \\
\hline Email tidak boleh kosong & $\mathrm{T}$ & $\mathrm{T}$ & $\mathrm{Ok}$ \\
\hline $\begin{array}{l}\text { Format pengetikan email tidak } \\
\text { sesuai (ex: jhongmail.com) }\end{array}$ & $\mathrm{F}$ & $\mathrm{F}$ & $\mathrm{Ok}$ \\
\hline $\begin{array}{l}\text { Alamat tidak boleh } \\
\text { dikosongkan }\end{array}$ & $\mathrm{T}$ & $\mathrm{T}$ & $\mathrm{Ok}$ \\
\hline $\begin{array}{l}\text { Nomor HP tidak boleh } \\
\text { dikosongkan }\end{array}$ & $\mathrm{T}$ & $\mathrm{T}$ & $\mathrm{Ok}$ \\
\hline $\begin{array}{l}\text { Format pengetikan nomor HP } \\
\text { tidak sesuai (bukan angka atau } \\
\text { mengandung huruf dan } \\
\text { karakter khusus) }\end{array}$ & $\mathrm{F}$ & $\mathrm{F}$ & $\mathrm{Ok}$ \\
\hline $\begin{array}{l}\text { Nomor KTP tidak boleh } \\
\text { kosong }\end{array}$ & $\mathrm{T}$ & $\mathrm{T}$ & $\mathrm{Ok}$ \\
\hline $\begin{array}{l}\text { Format pengetikan nomor KTP } \\
\text { tidak sesuai (bukan angka atau } \\
\text { mengandung karakter khusus) }\end{array}$ & $\mathrm{F}$ & $\mathrm{F}$ & $\mathrm{Ok}$ \\
\hline $\begin{array}{l}\text { Pilihan lokasi tidak boleh } \\
\text { kosong }\end{array}$ & $\mathrm{T}$ & $\mathrm{T}$ & $\mathrm{Ok}$ \\
\hline
\end{tabular}

\section{KESIMPULAN}

Kesimpulan dari hasil penelitian yang telah dilakukan adalah sebagai berikut:

a. Sistem informasi jasa fotografi telah berhasil dibangun menggunakan metode Extreme Programming. XP sangat tepat digunakan untuk menghadapi perubahan requirement yang 
cepat dari pengguna sehingga menjadi salah satu metode pengembangan sistem yang handal dalam membangun sebuah sistem.

b. Sistem informasi jasa fotografi mampu melayani order dari konsumen melalui form order yang tersedia didalam website, hal ini tentu saja memudahkan proses pencatatan transaksi pemesanan sehingga tidak perlu lagi dilakukan pencatatan pemesanan secara manual.

c. Sistem informasi jasa fotografi mampu menampilkan laporan pemesanan secara otomatis sehingga pencetakan laporan dapat lebih cepat dan mudah.

d. Sistem informasi jasa fotografi mampu menampilkan dan mencetak bukti bayar bagi pelanggan sehingga dapat mengurangi kekeliruan dalam pembuatan invoice.

\section{SARAN}

Dalam penelitian ini terdapat beberapa saran yang kiranya dapat di terapkan pada penelitian selanjutnya, diantaranya yaitu:

a. Perlu adanya CAPTCHA pada form order sebagai keamanan untuk menghindari penginputan oleh mesin.

b. Untuk kepentingan penelitian berikutnya bisa dilakukan pengujian terhadap sistem menggunakan metode ISO atau SQA agar pengujian lebih menyeluruh, tidak hanya sebatas pada fungsionalitas sistem.

\section{DAFTAR PUSTAKA}

[1] D. Andriansyah, "Pengujian Kotak Hitam Boundary Value Analysis Pada Sistem Informasi Manajemen Konseling Tugas Akhir,” vol. 7, no. 1, pp. 20-25, 2018, [Online]. Available: http://ijns.org/journal/index.php/ijns/article/view/1496.

[2] D. Andriansyah, "Pengukuran Kualitas Sistem Informasi Event Management Menggunakan Standard ISO 9126-1,” vol. 9, no. 1, pp. 1-7, 2017, [Online]. Available: http://ejurnal.net/portal/index.php/speed/article/view/1351.

[3] I. Suyadi, N. C. Pawestriningtyas, and Suharyono, "( Survei Pada Nasabah Perum Pegadaian Kantor Cabang Syariah Tlogomas Malang )," J. Adm. Bisnis, vol. 32, no. 2, pp. 2016, [Online]. A6, Available: http://administrasibisnis.studentjournal.ub.ac.id/index.php/jab/article/view/1262.

[4] T. Gumelar, R. Astuti, and A. T. Sunarni, "Sistem Penjualan Online Dengan Metode Extreme Programming,” J. Telemat., vol. 9, no. 2, pp. 87-90, 2017.

[5] N. Oktaviani and Hutrianto, "EXTREME PROGRAMMING SEBAGAI METODE PENGEMBANGAN E-KEUANGAN PADA PONDOK PESANTREN QODRATULLAH," no. 3, pp. 163-178, 2015.

[6] A. Supriyatna, "Metode Extreme Programming Pada Pembangunan Web Aplikasi Seleksi Peserta Pelatihan Kerja," J. Tek. Inform., vol. 11, no. 1, pp. 1-18, 2018, doi: 10.15408/jti.v11i1.6628.

[7] L. Rusdiana, "Extreme Programming untuk rancang bangun aplikasi pengelolaan surat keterangan kependudukan,” Regist. J. Ilm. Teknol. Sist. Inf., vol. 4, no. 1, p. 49, 2018, doi: 10.26594/register.v4i1.1191. 